\title{
TENANCY RENT CONTROL AND CREDIBLE COMMITMENT IN MAINTENANCE*
}

\author{
Richard Arnott ${ }^{\dagger} \quad$ Elizaveta Shevyakhova ${ }^{\ddagger}$
}

September 2008

\begin{abstract}
Under tenancy rent control, rents are regulated within a tenancy but not between tenancies. This paper investigates the effects of tenancy rent control on housing quality and maintenance. Since the discounted revenue received over a fixed-duration tenancy depends only on the starting rent, intuitively the landlord has an incentive to spruce up the unit between tenancies in order to "show" it well, but little incentive to maintain the unit well during the tenancy. The paper formalizes this intuition, and presents numerical examples illustrating the efficiency loss from this effect.
\end{abstract}

Keywords: tenancy rent control, rent control, maintenance, housing quality, credible commitment

JEL Classification: R21, R31, R38

\footnotetext{
* The authors would like to thank seminar participants at the MIT Real Estate Seminar and session participants at the 2005 North American Regional Science Association Meetings, especially the discussant, John Quigley, for useful comments on an earlier draft of the paper, and three referees and the editor for helpful criticism.

${ }^{\dagger}$ Corresponding Author (richard.arnott@ucr.edu). Department of Economics, University of California, Riverside, Riverside CA 92521

${ }^{\ddagger}$ Department of Economics, Boston College, Chestnut Hill, MA 02467
} 


\section{Tenancy Rent Control and Credible Commitment in Maintenance}

\section{Introduction}

Tenancy rent control is a form of rent control in which rents are regulated within a tenancy but may be raised without restriction between tenancies; more specifically, the starting rent for a tenancy is unregulated but the path of nominal rents within a tenancy, conditional on the starting rent, is regulated, typically causing rents to rise less rapidly over the tenancy than they would in the absence of controls ${ }^{1}$. Many, perhaps most, jurisdictions around the world that previously had traditional first- and second-generation rent control programs (Arnott, 1995) have moved in the direction of tenancy rent control as a method of partial decontrol ${ }^{2}$.

In jurisdictions that have stricter forms of rent control, tenancy rent control may be an attractive method of partial decontrol. Because the starting rent adjusts to clear the market, tenancy rent control does not generate the excess demand phenomena (such as key money, waiting lists, and discrimination) of stricter rent control programs, and should have a less adverse effect on the matching of households to housing units ${ }^{3}$. Tenancy rent control continues to provide sitting tenants with improved security of tenure; for one thing, rent regulation within tenancies precludes economic eviction; for another, because tenancy rent control, like other forms of rent control, provides landlords with an incentive to evict tenants, it is invariably accompanied by conversion (rehabilitation, demolition and reconstruction, and conversion to condominium) restrictions ${ }^{4}$. As well, tenancy rent control may be a politically attractive method of partial decontrol since it continues to provide rent protection to sitting tenants, who are typically the strongest opponents of decontrol. These benefits must be weighed against the costs. The most obvious costs are the tenant lock-in created by tenancy rent control and the unfairness of the preferential treatment of sitting tenants. There are also less obvious costs. The workability of tenancy rent control makes it more difficult to move to complete decontrol, should this be deemed desirable. Also, because a rent control administration is kept in place, it is relatively easy to return to harder controls should the political winds change. Landlords, fearing this, may curtail investment ${ }^{5}$.

This paper focuses on another less obvious cost of tenancy rent control - its adverse effect on maintenance. Pollakowski (1999) provides an empirical analysis of the effects of New York City's rent control system on housing maintenance there. Arnott and Johnston (1981) provides an informal,

\footnotetext{
${ }^{1}$ This defines the "ideal type", which is what will be modeled in this paper. Many jurisdictions have forms of rent control that are intermediate between tenancy rent control, according to the above definition, and more traditional forms of rent control. In some, rent increases are regulated both within and between tenancies, but less severely between tenancies than within tenancies. In others, rent increases are unregulated between tenancies but are subject to a variety of regulatory provisions within a tenancy, such as a guideline rent increase (which allows rents to rise by a certain percentage per year) with a cost-pass-through provision (which allows the landlord to apply for a rent increase above the guideline rent increase if justified by cost increases).

${ }^{2}$ Basu and Emerson (2000, 2003) and Arnott (2003) list some of these jurisdictions. Borsch-Supan (1996) models the current German system and Iwata (2002) the current Japanese system, both of which are termed "tenant protection" systems.

${ }^{3}$ There is a large literature on the adverse effects of rent control. Three particularly good papers that avoid polemical rent-control bashing are Frankena (1975), Glaeser and Luttmer (2003), and Olsen (1988).

${ }^{4}$ Miron and Cullingworth (1983) and Hubert (1991) examine the effects of rent control on security of tenure.

${ }^{5}$ These less obvious costs are evident in the Ontario experience with rent control (e.g., Smith, 2003).
} 
diagrammatic discussion of the effects of several rent control programs (though not tenancy rent control) on housing quality and maintenance. This paper will adapt the model of Arnott, Davidson, and Pines (1983) to examine how the application of tenancy rent control to a single atomistic landlord-builder affects his profit-maximizing behavior ${ }^{6}$.

Assume, as we will throughout most of the paper in order to abstract from the tenant lock-in effect, that tenancy duration is exogenous. There are two conflicting intuitions concerning the effects of tenancy rent control on the atomistic landlord's behavior. A lay person with good economic intuition would probably argue that tenancy rent control gives the landlord an incentive to spruce up his units between tenancies so that they "show" well and hence can be let at a higher starting rent, but little incentive to maintain the units well during tenancies since, after the starting rent has been agreed upon, maintaining well has no effect on the rent stream during the tenancy. An economist might however reasonably object that, with tenancy duration exogenous, there is nothing to prevent the landlord from following the program that is profit maximizing in the absence of tenancy rent control - which we shall term the efficient program. If the landlord follows this program, the tenant should be willing to pay as much over her tenancy as she would have for an uncontrolled unit. This line of reasoning suggests that, were it not for the tenancy lock-in, the landlord's profit-maximizing program would be unaffected by the application of tenancy rent control.

The resolution of the two conflicting intuitions lies in the ability of the landlord to credibly commit to the efficient program. If he is able to credibly commit to a maintenance program, he will credibly commit to the efficient program and the tenant will agree to pay the same in rent in discounted terms over the duration of the tenancy as in the absence of rent control. The landlord will therefore be making the same revenue and incurring the same costs as in the absence of rent control, and can surely do no better than this. Thus, if the landlord can credibly commit to the efficient program, tenancy rent control alters the timing of rent payments over a tenancy but generates no inefficiency.

If, however, the landlord is unable to credibly commit to pursuing the efficient program, once the lease is signed he has an incentive to pursue a different maintenance program, which we term the opportunistic program. Since the signing of the lease fixes the discounted rent the landlord will receive over the current tenancy, the only incentive he has to maintain is to improve the quality of the unit at the end of the lease, as this will increase the discounted rent he receives on subsequent tenancies. Compared to the efficient program, the opportunistic program entails both a reduction in average maintenance and a postponement of maintenance within a tenancy. Before the lease is signed, a prospective tenant should in this situation realize that under tenancy rent control the landlord will pursue the opportunistic rather than the efficient maintenance program and hence not be willing to pay as high a starting rent as she would if he were to pursue the efficient program.

The crux of the matter is therefore the landlord's ability, under tenancy rent control, to commit to a particular maintenance program. Three commitment mechanisms might be partially effective. The first is contracting on maintenance. One problem with this commitment mechanism is that, since maintenance is such an amorphous concept, maintenance clauses in the lease would be highly incomplete; for example, if the contract were to require the landlord to replace appliances every ten years, he might replace with appliances that are used and reconditioned or of minimal quality.

\footnotetext{
${ }^{6}$ Since the analysis is "very" partial equilibrium, it will ignore the effects of tenancy rent control on the level of rents and on other markets such as the labor market.

While the paper focuses on tenancy rent control, the techniques employed can be applied to examine the effects of other forms of rent control on the landlord's optimal program (indeed, Arnott and Johnston (1981) does so, albeit informally).
} 
Another problem is that it would be costly for a tenant to document that her landlord had not met the maintenance terms of the contract. The second commitment mechanism, reputation, is likely to be ineffective since the typical prospective tenant knows little or nothing about different landlords' maintenance performance when she is searching for a unit. The third mechanism, maintenance regulation, suffers from problems similar to those for contracting on maintenance. In our judgment, such commitment devices are generally ineffective, and in our analysis we shall assume them to be completely ineffective. The efficiency costs that we identify are reduced to the extent that these commitment mechanisms are indeed effective.

Section 2 presents a preliminary, stripped-down model that highlights the maintenance distortions caused by tenancy rent control when landlords are unable to credibly commit to the optimal program. Section 3 presents the central model in the absence of rent control, which is a particular case of Arnott, Davidson, and Pines (1983). Section 4 does the same as Section 2 but for the central model. Section 5 presents some calibrated examples focusing on the magnitude of the efficiency loss caused by tenancy rent control. Section 6 discusses relaxation of various assumptions and concludes.

\section{A Stripped-Down Version of the Model}

The central model is quite complex, employing optimal control theory. To elucidate the economics, we start out with a stripped-down model. This model considers the profit-maximizing maintenance choices of a landlord who buys a housing unit and then rents it out to the same tenant for two equal-length periods, at the end of which he sells the unit. The economic environment is stationary; the interest rate $r$, the market rent function $P(q)$, which relates per-period rent to housing quality, the property value function $V(q)$, which relates property value to quality, and the depreciation function, are all time invariant. Rent is received and maintenance undertaken at the beginning of each period, while housing is valued at the end of each period. When the landlord buys the housing unit, its quality is $q_{0}$. In the absence of maintenance the housing unit deteriorates in quality, and its deterioration is slowed or even reversed as more is spent on maintenance. The landlord's chooses the level of maintenance in each of the two periods so as to maximize the present value of profit. The maintenance technology is given by the depreciation function

$$
q_{t}=g\left(q_{t-1}, m_{t}\right)
$$

which states that quality during period $t$ is a function of quality during the previous period as well as maintenance undertaken at the beginning of period $t$. It is assumed that there are positive but diminishing returns to maintenance, and also that the higher the quality the more must be spent on maintenance to achieve a given level of depreciation $\left(q_{t-1}-q_{t}\right)$.

We first consider the landlord's profit-maximization problem without any rent control, and then with tenancy rent control.

\section{$2.1 \quad$ No rent control}

Without rent control, the landlord's profit-maximization problem is a familiar, two-period optimal investment problem with maintenance and scrap value. His present value of profit over the two 
periods is

$$
\Pi=P\left(q_{1}\right)+\frac{P\left(q_{2}\right)}{1+r}+\frac{V\left(q_{2}\right)}{(1+r)^{2}}-V\left(q_{0}\right)-m_{1}-\frac{m_{2}}{1+r} .
$$

Discounted profit equals the discounted rent received plus the discounted sale value, which depends on second-period quality, minus the purchase price of the unit minus discounted maintenance expenditure. The landlord maximizes (2) subject to (1). The economics of the problem are transparent when (1) is substituted into (2) yielding

$$
\Pi=P\left(g\left(q_{0}, m_{1}\right)\right)+\frac{P\left(g\left(g\left(q_{0}, m_{1}\right), m_{2}\right)\right)}{1+r}+\frac{V\left(g\left(g\left(q_{0}, m_{1}\right), m_{2}\right)\right)}{(1+r)^{2}}-m_{1}-\frac{m_{2}}{1+r}-V\left(q_{0}\right) .
$$

The first-order conditions for $m_{1}$ and $m_{2}$ are

$$
\begin{array}{ll}
m_{1}: & \left\{P^{\prime}\left(q_{1}\right)+\left[\frac{P^{\prime}\left(q_{2}\right)}{1+r}+\frac{V^{\prime}\left(q_{2}\right)}{(1+r)^{2}}\right] \frac{\partial q_{2}}{\partial q_{1}}\right\} \frac{\partial q_{1}}{\partial m_{1}}-1=0 \\
m_{2}: & \frac{1}{1+r}\left\{\left[P^{\prime}\left(q_{2}\right)+\frac{V^{\prime}\left(q_{2}\right)}{1+r}\right] \frac{\partial q_{2}}{\partial m_{2}}-1\right\}=0,
\end{array}
$$

where the partial derivatives are for the corresponding depreciation function. Spending a dollar more on first-period maintenance increases the present value of revenue in three ways. First-period quality increases by $\partial q_{1} / \partial m_{1}$, which increases first-period rent by $P^{\prime}\left(q_{1}\right)\left[\partial q_{1} / \partial m_{1}\right]$; second-period quality increases by $\left[\partial q_{2} / \partial q_{1}\right]\left[\partial q_{1} / \partial m_{1}\right]$, which increases discounted second-period rent by this amount times $P^{\prime}\left(q_{2}\right) /(1+r)$ and discounted sales price by this amount times $V^{\prime}\left(q_{2}\right) /(1+r)^{2}$. Eq. (4) indicates that maintenance should be carried to the point where the discounted revenue from the marginal dollar spent on maintenance equals one dollar. The interpretation of $(5)$ is analogous.

\subsection{Tenancy rent control}

Now consider the situation with tenancy rent control under the assumptions that the landlord cannot commit to a particular maintenance program prior to the signing of the lease and that the duration of the tenancy is exogenous. The landlord will first sign a lease with the tenant. Under tenancy rent control, the lease specifies a starting rent, and then the rent control formula determines the time path of rent over the tenancy as a function of the starting rent. Under the assumption that tenancy duration is exogenous, the discounted revenue over the tenancy is therefore determined when the lease is signed. And under the assumption that the landlord cannot commit to a particular

maintenance program, he makes his maintenance decisions taking the discounted revenue over the tenancy as fixed. In particular, he chooses the first- and second-period maintenance levels so as to maximize the discounted sales price of the property at the end of the lease minus the discounted maintenance expenditures:

$$
Z=\frac{V\left(g\left(g\left(q_{0}, m_{1}\right), m_{2}\right)\right)}{(1+r)^{2}}-m_{1}-\frac{m_{2}}{1+r} .
$$

The first-order conditions for $m_{1}$ and $m_{2}$ are 


$$
\begin{array}{ll}
m_{1}: & \frac{V^{\prime}\left(q_{2}\right)}{(1+r)^{2}} \frac{\partial q_{2}}{\partial q_{1}} \frac{\partial q_{1}}{\partial m_{1}}-1=0 \\
m_{2}: & {\left[\frac{V^{\prime}\left(q_{2}\right)}{(1+r)} \frac{\partial q_{2}}{\partial m_{2}}-1\right] /(1+r)=0 .}
\end{array}
$$

Eq. (7) states that the landlord will spend on first-period maintenance up to the point where the marginal dollar increases the discounted sales price of the unit by one dollar. Spending more on maintenance will not alter the rent he receives in either the first or second period. The interpretation of $(8)$ is analogous.

Comparing eqs. (4) and (7), it appears that first-period maintenance is lower under tenancy rent control since, unlike the unregulated situation, spending more on maintenance does not increase the present value of rent. The marginal benefit of first-period maintenance is lower with rent control than without, and the marginal cost is the same. Similarly, comparing (5) and (8), it appears that second-period maintenance is lower under tenancy rent control too. Thus, the application of tenancy rent control appears to discourage maintenance. We say "appears to" since the reasoning is based on a comparison of two single equations, each from a different system of equations ${ }^{7}$.

Comparing the pair of eqs. (4) and (7) and then (5) and (8), it appears as well that tenancy rent control also causes a postponement of maintenance. The application of rent control causes the marginal benefit of maintenance to shift down proportionally more for first-period than for secondperiod maintenance, since in the unregulated situation the effect of maintenance on discounted rent relative to its effect on sales price is larger in the first period than in the second.

The effects of tenancy rent control are actually more complicated than the above model suggests since the application of controls alters not only maintenance in the two periods but also the property value function. If tenancy rent control is applied to only a small portion of the relevant housing market (so that the demand for controlled housing at each quality level is perfectly elastic), then the deadweight loss associated with tenancy rent control is fully capitalized into the sales price function. If tenancy rent control is more broadly applied, determination of the effects of the controls on the sales price function requires a full general equilibrium analysis of the housing market.

\subsection{Comparison using specific functional forms}

The aim of this section is to illustrate that, when the landlord is unable to commit to a maintenance program, the application of tenancy rent control causes maintenance to be reduced and also postponed towards the end of the tenancy. This subsection develops a specific example illustrating these effects. We shall assume that: i) in the absence of rent control the rent function is $P(q)=f+h q$; ii) the depreciation function is $q_{t}=g\left(q_{t-1}, m_{t}\right)=(1-\delta) q_{t-1}+2 a \sqrt{m_{t}}$ for $t=1,2$; and iii) the sales price function is $V(q)=\beta+\gamma q$. In the absence of maintenance housing quality depreciates at the geometric rate $\delta$, and there are diminishing returns to maintenance. The rent and sales price functions are both linear.

\footnotetext{
${ }^{7}$ Consider the maximand $Y=\theta\left[P\left(g\left(q_{0}, m_{1}\right)\right)+\frac{P\left(g\left(g\left(q_{0}, m_{1}\right), m_{2}\right)\right)}{1+r}\right]+\frac{V\left(g\left(g\left(q_{0}, m_{1}\right), m_{2}\right)\right)}{(1+r)^{2}}-m_{1}-\frac{m_{2}}{1+r}$. With $\theta=1$, this is the maximand in the absence of rent control (except for a constant that does not affect the first-order conditions), and with $\theta=0$, the maximand under tenancy rent control. Thus, the two programs can be rigorously compared by totally differentiating the first-order conditions of $Y$ with respect to $\theta$.
} 


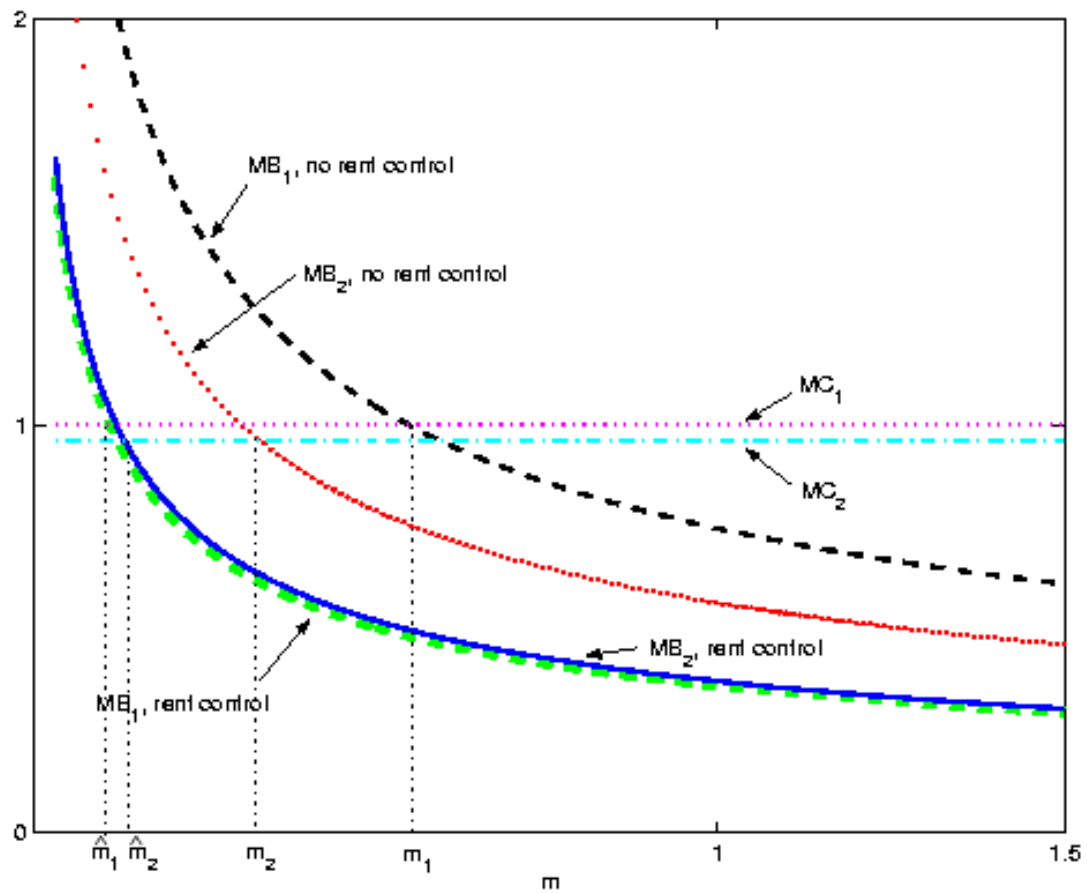

Figure 1: Discounted marginal benefit and marginal cost of maintenance in periods 1 and 2 with and without tenancy rent control. The parameter values are $h=1, \gamma=2, r=0.0375, a=0.2$, $\delta=0.03$.

Consider first the situation without rent control. Substituting $P^{\prime}(q)=h, V^{\prime}\left(q_{2}\right)=\gamma, \partial q_{2} / \partial q_{1}=$ $1-\delta$, and $\partial q_{t} / \partial m_{t}=a m_{t}^{-1 / 2}$ for $t=1,2$ into (4) and (5), and solving out for $m_{1}$ and $m_{2}$ gives

$$
\begin{gathered}
m_{1}=\left[\frac{\gamma(1-\delta) a}{(1+r)^{2}}+h a+\frac{h(1-\delta) a}{1+r}\right]^{2} \\
m_{2}=\left[\frac{\gamma a}{1+r}+h a\right]^{2}
\end{gathered}
$$

Thus, as intuition would suggest, the profit-maximizing level of maintenance in both periods is higher, the steeper the rent and sales price functions, the more effective the maintenance (measured by $\alpha$ ), and the lower the discount rate. First-period maintenance is also higher the lower is the depreciation rate, $\delta$, since with a lower depreciation rate first-period maintenance has a larger effect on second-period quality and therefore sales price and second-period rent.

Proceeding analogously, we obtain that under tenancy rent control

$$
\hat{m}_{1}=\left[\frac{\gamma(1-\delta) a}{(1+r)^{2}}\right]^{2}
$$




$$
\hat{m}_{2}=\left[\frac{\gamma a}{1+r}\right]^{2}
$$

where ${ }^{\wedge}$ denotes the value of a variable with rent control. Comparison of (9) and (11) indicates that the application of tenancy rent control lowers first-period maintenance, and comparison of (10) and (12) that tenancy rent control lowers second-period maintenance too. From (9) to (12), we also obtain that

$$
\frac{\hat{m}_{1}}{\hat{m}_{2}}=\left[\frac{1-\delta}{1+r}\right]^{2}<\left[\frac{1-\delta}{1+r}+\frac{h}{\frac{\gamma}{1+r}+h}\right]^{2}=\frac{m_{1}}{m_{2}}
$$

so that rent control not only reduces maintenance in each period but also tilts maintenance towards the second period of the tenancy.

The above model is incomplete since it explains neither how the housing unit of quality $q_{0}$ came into being, nor how the property value function is determined. We could close the model by introducing housing construction, but have chosen to do this in the context of the central model, to which we now turn.

\section{The Central Model without Rent Control}

The central model differs from the stripped-down model in treating time as continuous. This allows optimal control theory and phase plane analysis to be applied, and permits a neat and transparent closing of the model.

A competitive landlord-builder owns a vacant lot on which only a single unit of housing can be constructed $^{8}$. Housing is durable and its quality is endogenous. Multiple quality-changing technologies are in principle available, including construction, maintenance, demolition and reconstruction, and rehabilitation. The economic environment is stationary and described by the quality-changing technologies, the rent function relating market rent to quality, and the interest rate. The maintenance technology is autonomous - the unit's rate of quality change depends on its current quality and the current level of maintenance expenditure but not on the unit's age per se. The landlord chooses the profit-maximizing program. Under these assumptions, phase plane analysis shall be employed.

A general analysis of "the landlord's problem" is presented in Arnott, Davidson, and Pines (1983). We focus on the practically most realistic case in which, in the absence of controls, at the beginning of the program it is profit maximizing to construct and then to downgrade to saddlepoint quality. In the working paper (Arnott and Shevyakhova, 2007), the quality-changing technologies permitted three qualitatively different active programs: initial construction followed by downgrading to saddlepoint quality, a construction-downgrading-demolition cycle, and initial construction followed by a downgrading-rehabilitation cycle. We showed there, as intuition would suggest, that which program is profit maximizing depends on the relative costs of maintenance, construction, and rehabilitation. Here, to simplify, we restrict the analysis to the case of initial construction followed by

\footnotetext{
${ }^{8}$ The analysis can be extended straightforwardly to endogenize structural density (Arnott, Davidson, and Pines, 1986).
} 
downgrading to saddlepoint quality, essentially assuming that, both with and without rent control, this program is profit maximizing, which occurs when maintenance is cheap relative to construction and rehabilitation, and is broadly consistent with one variant of the classical filtering hypothesis, which states that in an unregulated housing market, actual quality-changing technologies are such that housing deteriorates as it ages ${ }^{9}$.

\subsection{Analysis of optimal program without rent control}

At time 0 the landlord constructs a single housing unit of quality $q_{c}$ on his lot and then downgrades the unit asymptotically to saddlepoint quality $q^{S}$. Where $q(t)$ is quality at time $t, P(q)$ the exogenous rent function, $m(t)$ maintenance expenditure at time $t, r$ the interest rate, $\alpha$ construction cost per unit of quality, $g(q, m)$ the depreciation function ${ }^{10}$, and $T$ the terminal time, the profitmaximizing program without rent control is the solution to

$$
\begin{aligned}
& \max _{q_{c}, m(t)} \int_{0}^{\infty}(P(q(t))-m(t)) e^{-r t} d t-\alpha q_{c} \\
& \text { i) } \dot{q}=g(q, m) \\
& \text { s.t. } \quad \text { ii) } \quad q_{c} \equiv q(0) \quad \text { free } \\
& \text { iii) } \lim _{T \uparrow \infty} q(T) \text { free }
\end{aligned}
$$

Note that quality is measured as some fraction of construction costs, and that tenant maintenance is not considered. We impose non-negativity conditions on $q$ and $m$. Where 's denote derivatives and subscripts partial derivatives, we also impose reasonable restrictions on the functions $P$ and $g$ : i) $P(0)=0, P^{\prime}(q)>0$ and $P^{\prime \prime}(q)<0$; and ii) $g_{q}<0, g_{m}(q, 0)=\infty, g(q, 0)<0, g_{m}(q, \infty)=0$, $g_{m}>0, g_{m m}<0$. Thus, rent increases with quality but at a diminishing rate; there are positive but diminishing returns to maintenance; holding fixed the rate of quality deterioration, more has to be spent on maintenance as quality increases; and with zero maintenance, the unit deteriorates. In our numerical examples, the first-order conditions of the optimal program will define a unique interior maximum.

We solve the problem using optimal control theory (Kamien and Schwartz, 1991). The current-value Hamiltonian corresponding to (13) is

$$
\mathcal{H}^{\circ}=P(q(t))-m(t)+\phi(t) g(q(t), m(t)),
$$

where $\phi(t)$ is current-value co-state variable on $\dot{q}=g(q, m)$. The first-order condition ${ }^{11}$ for maintenance is

$$
-1+\phi(t) g_{m}(q(t), m(t))=0
$$

Since $\phi(t)$ is the marginal value of quality at time $t$, and $g_{m}(q(t), m(t))$ the amount by which quality is increased by an extra dollar's expenditure on maintenance, $\phi g_{m}$ is the marginal benefit

\footnotetext{
${ }^{9}$ There are many different variants of the filtering hypothesis. Another states that in an unregulated housing market, a housing unit is occupied by relatively poorer households as it ages. Another way of saying this is that it is efficient for the poor to live in hand-me-down housing. This variant of the filtering hypothesis has been central to economic arguments against public housing, since public housing entails the construction of new housing for the poor.

${ }^{10} g(q, m)$ is actually the negative-of-depreciation function.

${ }^{11}$ Throughout the analysis we shall omit second-order conditions but we check that they are satisfied in our numerical examples.
} 
from maintenance. Thus, at each point in time, maintenance should be such that marginal benefit equals marginal cost. The conditions imposed on $g_{m}$ guarantee that there is a unique, interior optimal level of maintenance expenditure for all non-negative values of $q$ and $\phi$; thus, we may write $m=m(q, \phi)$ with $m_{\phi}>0$. Inserting this function into (14) yields the maximized current-value Hamiltonian:

$$
\mathcal{H}(q, \phi)=P(q)-m(q, \phi)+\phi g(q, m(q, \phi)) .
$$

The equation of motion of the co-state variable is

$$
\dot{\phi}=r \phi-\mathcal{H}_{q}=r \phi-P^{\prime}-\phi g_{q}
$$

The assumptions thus far have not ruled out the possibility that the optimal saddlepoint program entails upgrading to saddlepoint quality via maintenance alone. We assume that the maintenance and construction technologies are such that the optimal saddlepoint program entails construction at the start of the program. The transversality condition with respect to $q_{c}$ is then

$$
\phi(0)=\alpha
$$

construction quality should be increased up to the point where the marginal value of quality equals its marginal cost.

We are now in a position to construct the phase plane corresponding to this program. We assume that: i) the $\dot{q}=0$ locus is positively sloped; ii) the $\dot{\phi}=0$ locus is negatively sloped; and iii) the $\dot{q}=0$ locus and $\dot{\phi}=0$ locus intersect in the positive orthant. Thus, there is a unique saddlepoint, $S=\left(q^{S}, \phi^{S}\right)$. We assume furthermore that $\phi^{S}>\alpha$. Figure 2 displays a phase plane consistent with these assumptions. As is the case for all subsequent figures, Figure 2 is drawn for the functional forms and parameters used in the base-case numerical example presented in Section 5.

We also have the infinite horizon transversality conditions associated with terminal quality and terminal time. Arnott, Davidson, and Pines (1983) proves that, under the assumptions made, these conditions imply that the optimal trajectory must terminate at the saddlepoint. Putting together the necessary conditions for optimality, we obtain that the optimal program entails construction at that quality at which the right stable arm intersects the $\phi=\alpha$ line, $q_{A}$, followed by downgrading along the stable arm to the saddlepoint.

For an autonomous optimal control problem with discounting, the value of the program at any time along an optimal trajectory equals the value of the Hamiltonian at that time divided by the interest rate:

$$
V(t)=\frac{\mathcal{H}(q(t), \phi(t))}{r} .
$$

The economic interpretation is that the value of the Hamiltonian gives the economic return per unit time from owning the property, which includes the net (of expenses and depreciation) earnings stream it generates plus capital gains, and competitive asset pricing requires that the net return per unit time from owning an asset equal the asset price times the discount rate.

With some abuse of notation, we denote the value of the maximized Hamiltonian at a point labeled $X$ in the phase plane by $\mathcal{H}(X)$. The value of the program immediately after initial construction is then $\frac{\mathcal{H}(A)}{r}$, so that the value of the program immediately before initial construction, which is the value of the program, is $V^{*}=\frac{\mathcal{H}(A)}{r}-\alpha q_{A}$. 


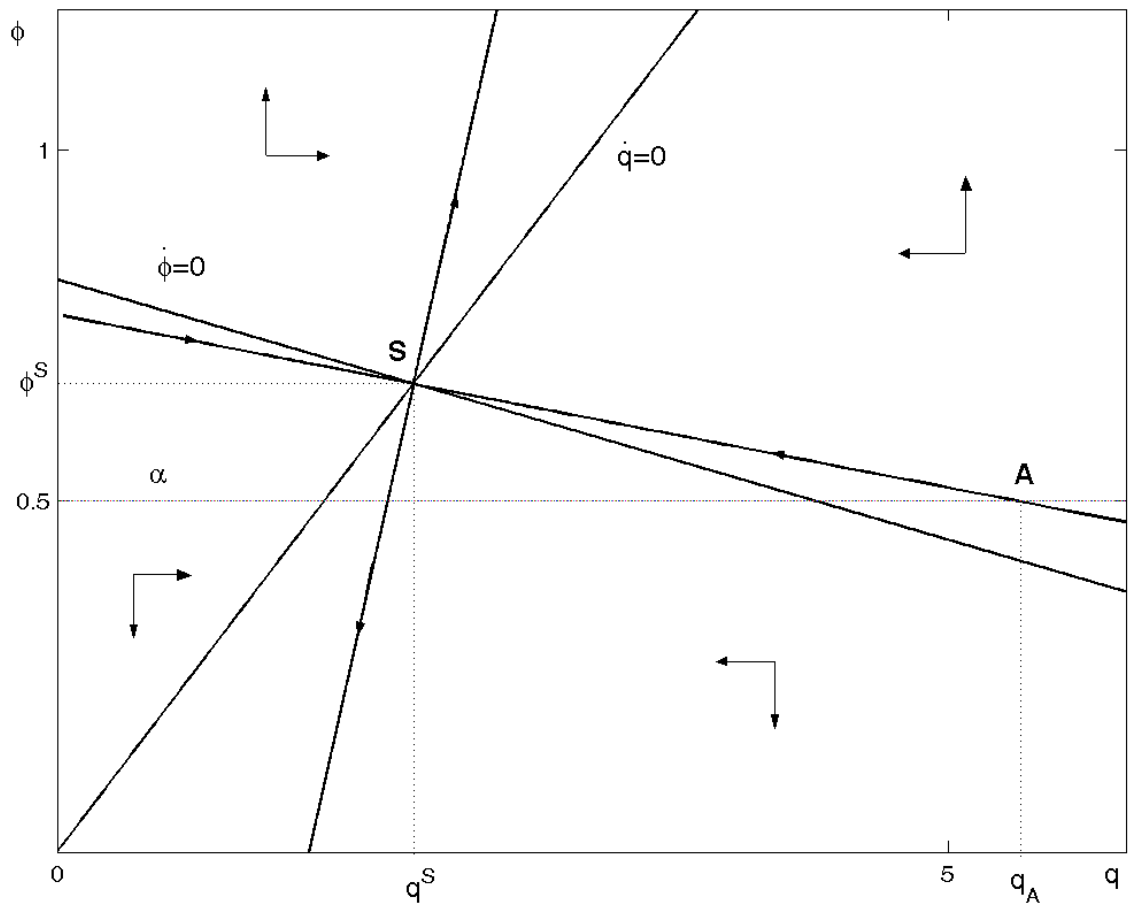

Figure 2: Phase plane for construction with downgrading to the steady state.

\section{Tenancy Rent Control}

We model tenancy rent control as a ceiling on the time path of rents over the duration of a tenancy, conditional on the starting rent ${ }^{12}$. Letting $p_{s}$ denote the starting rent, $u$ the length of time into the tenancy, and $F\left(p_{s}, u\right)$ (with $\partial F / \partial p_{s}>0$ ) the rent control function - the maximum allowable rent $u$ years into a tenancy, conditional on $p_{s}-$ a tenancy rent control program imposes the constraint that $\widehat{P}(u) \leq F\left(p_{s}, u\right)$, where $\widehat{P}(u)$ is the rent charged by the landlord $u$ years into the tenancy.

\subsection{Assumptions}

We shall examine the effects of tenancy rent control applied to a single housing unit when all other units are uncontrolled; the analysis is therefore partial equilibrium. We make a number of simplifying assumptions:

Assumption 1 The length of a tenancy is exogenous at $L$.

\footnotetext{
${ }^{12}$ There are tenancy rent control programs that restrict the percentage increase in rent from one year to the next. Under such a program, a landlord might find it profit maximizing to charge less than the maximum allowable rent increase for some time interval during a tenancy, in which case the ceiling on the time path of rents would thereafter be determined by the rent level at the time the percentage increase regulation again becomes binding. Thus, our modeling of tenancy rent control entails a simplification.
} 
This assumption is made for two reasons. First, we wish to abstract from the effect of tenancy rent control on tenancy duration, in order to focus on its effects on landlord maintenance and conversion. Second, the assumption takes into account that tenancy rent control is invariably accompanied by restrictions on eviction ${ }^{13}$. Since tenancy rent control front-end loads rent over a tenancy, shorter tenancies are more profitable for landlords. In the absence of restrictions on eviction, tenancy rent control would therefore provide landlords with an incentive to evict tenants ${ }^{14}$.

Assumption 2 The rent control function is such that the landlord finds it profit maximizing to charge the maximum controlled rent over the duration of a tenancy, i.e. $\widehat{P}(u)=F\left(p_{s}, u\right)$.

This assumption states that, under the opportunistic program, the time path of controlled rents over a tenancy are sufficiently front-end loaded relative to the time path of market rents that the tenancy rent control constraint binds strictly throughout the tenancy. While not primitive, this assumption greatly simplifies the analysis since otherwise the possibility would have to be considered that the rent control constraint binds over some quality intervals but not over others.

\section{Assumption 3 Tenants are identical.}

Assumption 4 Tenants face perfect capital markets and discount financial flows at the same rate as the landlord.

With identical tenants, the market rent as a function of quality adjusts so that a renter receives the same utility at all quality levels. Thus, under tenancy rent control, a tenant is indifferent between living in a controlled and uncontrolled unit if and only if the discounted value of controlled rents over the tenancy equals the discounted value of market rents for the same quality path, discounted at her discount rate. The assumption that the tenant's discount rate is the same as the landlord's is made to simplify the analysis.

Under the above assumptions, the opportunistic program is independent of the form of the rent control function. A proof runs as follows. Suppose that the profit-maximizing program with a particular rent control function has been solved for. Now modify the rent control function, holding constant the time path of maintenance, and therefore of quality, but allowing the starting rents for each tenancy to adjust so that tenants remain indifferent between controlled and uncontrolled housing. The profitability of the program remains unchanged and the landlord cannot improve profitability by altering the program. Without ambiguity, we may then let $\hat{q}\left(u ; q_{s}\right)$ denote the time path of quality over a tenancy under the opportunistic program, conditional on starting quality $q_{s}$. And the condition that, with the opportunistic program, over each tenancy the discounted value of controlled rents equals the discounted value of market rents may be written as

\footnotetext{
${ }^{13}$ We use the term eviction to mean that the tenant is required to leave her unit even though she would prefer not to, rather than in the legal sense.

${ }^{14}$ Tenancy rent control rules out economic eviction (raising rents to force a tenant out) but at least in North America, where annual tenancies are the norm, a landlord can evict a tenant in some jurisdictions simply by choosing not to renew the lease, and in others by citing as just causes minor lease violations or his intention to lease the unit to a family member, convert it to owner occupancy, or rehabilitate it. Recall that the working paper analyzes the situations where a demolition cycle or rehabilitation is most profitable. Assumption 1 implies that, under tenancy rent control, the landlord is able to demolish or to rehabilitate only between tenancies.
} 


$$
\int_{0}^{L} F\left(p_{s}, u\right) e^{-r u} d u=\int_{0}^{L} P\left(\widehat{q}\left(u ; q_{s}\right)\right) e^{-r u} d u .
$$

Thus, under the above assumptions, it is the imposition of tenancy rent control rather than its severity $^{15}$ that matters since it is the imposition of tenancy rent control that undermines the credibility of the efficient program.

In the previous section we assumed that, in the absence of rent control, it is profit maximizing for the landlord to construct and then downgrade to saddlepoint quality. In this section we assume that this is profit-maximizing under tenancy rent control as well. Put alternatively, we assume that maintenance is sufficiently cheap relative to construction and rehabilitation that both with and without rent control the most profitable course of action for the landlord is to construct and then downgrade to saddlepoint quality.

\subsection{Analysis of optimal program with rent control}

The profit-maximizing program with rent control, too, entails construction followed by downgrading from one tenancy to the next, but maintenance follows a sawtooth pattern, increasing within each tenancy and then falling discontinuously from the end of one tenancy to the start of the next. The program converges to a steady-state tenancy maintenance cycle in which quality is highest at the beginning and end of each tenancy, rather than to a steady-state quality.

We decompose solution of the opportunistic program under tenancy rent control during a single tenancy into two stages. In the first stage, we solve the program taking as given not only the initial quality of the unit and the duration of the tenancy but also the terminal quality. In the second stage, we solve for the profit-maximizing terminal quality. The landlord decides on this program after the lease has been signed, and therefore after his discounted rent over the tenancy has been determined. The first-stage problem entails the minimization of discounted maintenance expenditures needed to achieve terminal quality, $q_{L}$, taking as given the starting quality, $q_{s}$, and the tenancy duration, $L$. This is an elementary optimal control program with a well-known solution. Define $J\left(q_{s}, q_{L}, L\right)$ to be the value of this program. We shall use three properties of the solution:

$$
\partial J / \partial q_{s}=\phi(0) \quad \partial J / \partial q_{L}=-\phi(L) e^{-r L} \quad \dot{\phi}=r \phi-\phi g_{q}
$$

where $\phi(t)$ is the current value of the co-state variable on $\dot{q}=g(q, m)$. The first solution property indicates that $\phi(0)$ is the marginal value of quality at the start of the tenancy, after the tenancy contract has been signed. The second indicates that $\phi(L)$ is the marginal value of terminal quality at terminal time, so that $\phi(L) e^{-r L}$ is the marginal value of terminal quality discounted to the beginning of the tenancy. Since the first stage of the problem entails deciding on the maintenance path over the tenancy, after the contract has been signed, we refer to $\phi$ as the ex post (viz., after the tenancy contract has been signed) marginal value of quality. The last solution property is that over a tenancy the ex post marginal value of quality grows ${ }^{16}$ at the rate $r-g_{q}$ through the tenancy.

\footnotetext{
${ }^{15} \mathrm{~A}$ tenancy rent control program is more severe than another if it permits a lower nominal percentage increase in rent every year during a tenancy. Assumption A.2 is that the tenancy rent control program is sufficiently severe that the landlord finds it profit maximizing to charge the maximum controlled rent over the duration of the tenancy. If the tenancy rent control program is sufficiently "lax" that the landlord finds it profit maximizing to charge the maximum controlled rent over no portion of the tenancy, the program has no effect. Intermediate situations are analytically messy.

${ }^{16}$ Suppose the landlord buys an extra unit of quality today at a price of $\phi$. Instantaneously, he must make
} 
The second stage of the solution of the opportunistic program entails the choice of $q_{L}$. To derive this, we work with a value function. Under tenancy rent control, the value of a housing unit is a function not only of quality but also of how much time remains in the current tenancy contract ${ }^{17}$. Let $\widehat{V}(q)$ denote the value of a housing unit of quality $q$ between tenancies, and $Z\left(q_{s}\right)$ the revenue received over a tenancy contract, discounted to the beginning of the tenancy contract. The landlord decides on the maintenance program, and hence $q_{L}$, after signing the tenancy contract, and therefore after the revenue received over the tenancy has been determined. Then the value function $\widehat{V}(q)$ may be written as

$$
\widehat{V}\left(q_{s}\right)=Z\left(q_{s}\right)+\max _{q_{L}}\left[J\left(q_{s}, q_{L}, L\right)+\widehat{V}\left(q_{L}\right) e^{-r L}\right] .
$$

Terminal quality is chosen to maximize the expression in square brackets. The corresponding first-order condition is

$$
\partial J / \partial q_{L}+\widehat{V}^{\prime}\left(q_{L}\right) e^{-r L}=0 .
$$

Comparing the second equation in (19) and (21) yields

$$
\phi(L)=\widehat{V}^{\prime}\left(q_{L}\right) .
$$

Differentiating (20) with respect to $q_{s}$ yields

$$
\begin{aligned}
\widehat{V}^{\prime}\left(q_{s}\right) & =Z^{\prime}\left(q_{s}\right)+\partial J / \partial q_{s} \quad(\text { using the envelope theorem) } \\
& =Z^{\prime}\left(q_{s}\right)+\phi(0) \quad(\text { using }(19)) .
\end{aligned}
$$

Eq. (23) requires some care in interpretation. $\widehat{V}^{\prime}\left(q_{s}\right)$ is the ex ante (before the tenancy contract has been signed) marginal value of quality at the start of a tenancy, while $\phi(0)$ is the ex post (after the tenancy contract has been signed) marginal value of quality at the start of a tenancy. Eq. (23) indicates that, at starting quality, the ex ante marginal value of quality exceeds the ex post marginal value of quality by $Z^{\prime}\left(q_{s}\right)$, marginal discounted revenue. Thus, there is a downward jump discontinuity in the marginal value of quality at the time the lease is signed. Now return to (22). It states that, in contrast, the marginal value of quality immediately before the termination of the tenancy equals the marginal value of quality immediately afterwards, in both cases equaling the increase in the sales price from a unit increase in terminal quality.

The value of the program immediately prior to construction is

$$
\widehat{V}^{*}=\max _{q_{c}}\left[\widehat{V}\left(q_{c}\right)-\alpha q_{c}\right] .
$$

Assuming an interior solution, the corresponding first-order condition for profit-maximizing construction quality is

$$
\widehat{V}^{\prime}\left(q_{c}\right)-\alpha=0 .
$$

Comparing (23) and (25), for the first tenancy, since $q_{c}=q_{s}$,

$$
\phi(0)=\alpha-Z^{\prime}\left(q_{c}\right) .
$$

the competitive return on that unit, $r \phi$, and the return comprises two components, the capital gain, $\dot{\phi}$, minus the depreciation, $-\phi g_{q}$.

${ }^{17}$ Since the housing market remains competitive under rent control, it must still be the case that owning the property for an increment of time between $u$ and $u+d u$ within a tenancy provides income of $r V(q(u), u)$, where $V(q(u), u)$ is the market value of a controlled housing unit of quality $q u$ units of time into a tenancy. From this relationship, the rent control function, and the boundary condition that $\widehat{V}\left(q_{s}\right)=V\left(q_{s}, 0\right), V(q(u), u)$ may be calculated. 


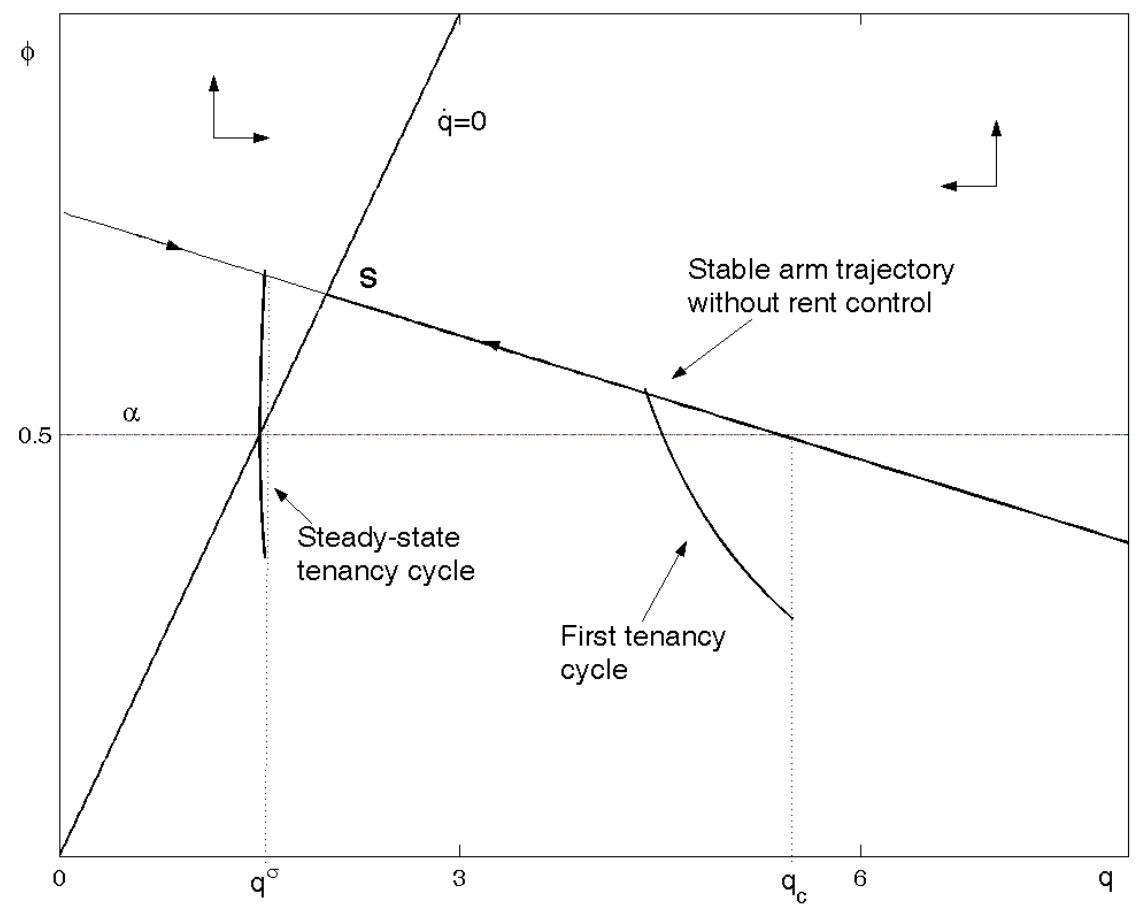

Figure 3: Phase plane for construction-downgrading to the steady-state cycle under rent control.

Construction occurs at that quality level for which the ex ante marginal value of quality via construction equals the marginal cost, while the ex post marginal value of construction quality falls short of marginal construction cost by $Z^{\prime}\left(q_{c}\right)$.

In the steady state, quality varies within a tenancy, but the starting and terminal qualities remain constant from one tenancy to the next. Let $q_{\sigma}$ be the optimal starting and terminal quality of a steady state cycle. Since in a steady-state tenancy $q_{s}=q_{L}=q_{\sigma}$,

$$
\widehat{V}\left(q_{\sigma}\right)=\frac{1}{1-e^{-r L}}\left\{Z\left(q_{\sigma}\right)+J\left(q_{\sigma}, q_{\sigma}, L\right)\right\} .
$$

Figure 3 displays the phase diagram of the optimal program under rent control for the numerical example, and plots the optimal trajectory for two tenancies, the first tenancy that occurs immediately after construction and the steady-state tenancy. For comparison it also plots the optimal (stable arm) trajectory without rent control. With the depreciation function we employ, maintenance expenditures are positively related to $\phi$ and independent of $q$. The diminished incentive to maintain under tenancy rent control is reflected in the lower position, on average, of the optimal trajectory under tenancy rent control. The incentive under tenancy rent control to postpone maintenance expenditures towards the end of the tenancy is also evident. 


\section{$5 \quad$ Numerical Examples}

This section presents a series of related numerical examples with the aim of quantifying the effects of tenancy rent control. The efficiency loss caused by the commitment problem is of special interest.

\subsection{Choice of functional forms and parameters}

We had hoped to draw on the empirical literature in our choice of functional forms and parameters. Unfortunately, there seem to be no empirical studies that have employed the Arnott, Davidson, and Pines (1983) conceptual framework as the basis for empirical analysis. As a result, we adopt the more modest goal of developing numerical examples whose parameters and functional forms are "reasonable". We chose the functional forms so as to obtain equations of motion that are the solutions to linear differential equations, as well as (for the case of rent control) closed-form value functions. And we chose the parameters to generate plausible results.

As in the theoretical analysis, we measure quality as proportional to construction costs. We assume the following functional forms for the rent function, the construction cost function $C(q)$, and the depreciation function:

$$
P(q)=e q-\frac{f q^{2}}{2} \quad C(q)=\alpha q \quad \dot{q}=-\delta q+2 a m^{1 / 2}
$$

The rent equation generates a linear, downward-sloping marginal-willingness-to-pay-for-quality function. The depreciation function is about the simplest possible. In the absence of maintenance, quality depreciates exponentially at the rate $\delta$. A given level of maintenance expenditure slows down the rate of quality depreciation by an amount that is independent of quality, and there are diminishing returns to maintenance. The optimal expenditure on maintenance is given by $a^{2} \phi^{2}$; maintenance expenditure is therefore increasing in $\phi$ and independent of $q$. Substituting the expression for optimal maintenance into the depreciation function gives the maximized depreciation function,

$$
\dot{q}=-\delta q+2 a^{2} \phi
$$

In the absence of rent control, these equations imply a co-state equation of the form

$$
\dot{\phi}=(r+\delta) \phi-e+f q,
$$

and with tenancy rent control ${ }^{18}$,

$$
\dot{\phi}=(r+\delta) \phi
$$

In the absence of rent control, these equations of motion correspond to a phase plane with a linear, upward-sloping $\dot{q}=0$ line and a linear, downward-sloping $\dot{\phi}=0$ line, whose intersection point, the saddlepoint, is at

$$
q^{S}=\frac{2 a^{2} e}{\delta(r+\delta)+2 a^{2} f} \quad \phi^{S}=\frac{e \delta}{\delta(r+\delta)+2 a^{2} f} .
$$

\footnotetext{
${ }^{18}$ Thus, both with and without rent control, the state and co-state equations are together a pair of linear firstorder differential equations in $q$ and $\phi$. In the absence of rent control, substituting one into the other generates linear, second-order differential equations for $q$ alone and $\phi$ alone. And with rent control, (29) is a linear, first-order differential equation in $\phi$ alone, and substituting the solution to (29) into (27) results in a linear, first-order differential equation in $q$ alone.
} 
With rent control, the $\dot{\phi}=0$ line coincides with the $q$-axis, so that the $\dot{q}=0$ and $\dot{\phi}=0$ lines do not intersect in the interior of the phase plane.

We take as our units of measurement years and hundreds of thousands of dollars. Our assumed base-case parameters are:

$$
\delta=0.03, r=0.0375, a=0.2121, e=0.055, f=0.005, L=10, \text { and } \alpha=0.5 .
$$

These parameters imply a saddlepoint quality of 2.0, saddlepoint maintenance of 0.02 (\$2000 per year), saddlepoint rent of 0.10 (\$10000 per year), and a value of the co-state variable (the marginal value of quality) at the saddlepoint of 0.667 .

As the model has been specified, the "cap rate" (the capitalization rate, the ratio of rent net of expenditures to property value) equals the interest rate. In the absence of rent control, the property value - the value of the program - at saddlepoint quality equals rent net of maintenance expenditures, all divided by the cap rate, $\$ 213,333$. Thus, at the saddlepoint, the ratio of annual maintenance expenditures to property value is slightly under $1 \%$, which is broadly consistent with the $1 \%$ rule of real estate management, which states that annual maintenance expenditures on a building average around $1 \%$ of building value. If a housing unit were constructed at saddlepoint quality, it would cost $\$ 100,000$ to build. Thus, property value minus structure costs is $\$ 113,333$, and the ratio of construction cost to property value is 0.53 , which is reasonable.

While our base-case parameter values lead to reasonable results, we have little confidence in them, since there has been little empirical work estimating the parameters of the maintenance technology ${ }^{19}$, and since the other demand and construction cost parameters can be expected to exhibit considerable geographic variation: $\alpha$ depends on labor costs, the cost of construction materials, and the climate, and the demand parameters vary considerably not only across metropolitan areas but also within each metropolitan area, reflecting differences in local amenities and accessibility. To take into account our uncertainty about parameters, we shall investigate the sensitivity of the numerical results to parameter variation, within the subset of parameter values for which the saddlepoint program is the most profitable both with and without rent control.

\subsection{Numerical solution procedures}

The details of the numerical solution procedures employed are presented in the Appendix of Arnott and Shevyakhova (2007). Here we just describe in broad terms the general approaches. In the absence of rent control, the solution procedure centers on solving for the parameters of a secondorder linear differential equation for $\phi$, since everything else can be solved for once these parameters are obtained. One parameter is obtained from the initial condition that $\phi(0)=\alpha$, and (in the case of the saddlepoint program, on which we focus in this version of the paper) the second parameter is obtained from the $\phi$ coordinate of the saddlepoint.

The approach taken to solve the optimal program with tenancy rent control is more complex. It is convenient to express the unknown parameters in the functions $\phi(t)$ and $q(t)$ in terms of $q(0)$ and $q(L)$. This allows us to obtain the discounted revenue received over a tenancy, $Z\left(q_{s}\right)$, and the net

\footnotetext{
${ }^{19}$ Rothenberg et al. (1991) estimate a housing market model whose specification draws heavily on the Sweeney (1974a) filtering model, which conceptualizes the landlord's problem in much the same way as Arnott, Davidson, and Pines (1983) except that it treats housing quality as discrete rather than continuous and assumes that housing deteriorates in quality as it ages.
} 
value of a tenancy cycle, $J\left(q_{s}, q_{L}, L\right)$. We then make a conjecture about the form of $\hat{V}(q)$. Next, using (21) to determine $q_{L}\left(q_{s}\right)$ and plugging it into (20) we apply the method of undetermined coefficients to solve for $\hat{V}(q)$. The final step is to find the construction quality, $q_{c}$, using (25).

\subsection{Examples}

We record the results of our numerical examples in Tables $1 \mathrm{~A}$ and $1 \mathrm{~B}$. Table $1 \mathrm{~A}$ gives the results in the absence of rent control, and Table 1B those with tenancy rent control. With the functional forms assumed: from (27) the $\dot{q}=0$ line is $\phi=\frac{\delta q}{2 a^{2}}$; the $\dot{\phi}=0$ line is $\phi=\frac{e-f q}{r+\delta}$ without rent control (from (28)) and $\phi=0$ with rent control (from (29)); and expressions for the saddlepoint $q$ and $\phi$ are given in expressions below (29).

Table 1A: How the efficient program changes with a $10 \%$ increase in individual parameters - No rent control

\begin{tabular}{|c|c|c|c|c|c|c|c|}
\hline & base case & $\alpha=0.55$ & $r=0.04125$ & $\delta=0.033$ & $a=0.23331$ & $e=0.0605$ & $f=0.0055$ \\
\hline$q_{s}$ & 5.3972 & 4.3780 & 4.8186 & 5.0929 & 5.2537 & 6.9561 & 4.8439 \\
\hline$V\left(q_{s}\right)$ & 4.1150 & 3.5800 & 3.5381 & 3.7995 & 4.1268 & 5.5142 & 3.7462 \\
\hline $\begin{array}{l}V\left(q_{s}\right)-\alpha q_{s} \\
\quad=S V\end{array}$ & 1.4164 & 1.1721 & 1.1288 & 1.2531 & 1.4999 & 2.0362 & 1.3242 \\
\hline$m\left(q_{s}\right)$ & 0.0113 & 0.0136 & 0.0113 & 0.0113 & 0.0136 & 0.0113 & 0.0113 \\
\hline$q^{S}$ & 2.0 & 2.0 & 1.9130 & 1.7828 & 2.3304 & 2.20 & 1.9643 \\
\hline$m\left(q^{S}\right)$ & 0.0200 & 0.02 & 0.0183 & 0.0192 & 0.0224 & 0.0242 & 0.0193 \\
\hline$V\left(q^{S}\right)$ & 2.1333 & 2.1333 & 1.8853 & 1.8901 & 2.4573 & 2.5813 & 2.0835 \\
\hline
\end{tabular}

The first column of numbers in each table applies for the base-case parameter values. We have already commented on the base-case program without rent control. How the application of rent control affects the optimal program has been shown in Figure 3. Construction quality rises very slightly, from 5.40 to 5.49. Steady-state quality (measured as $q^{S}$ without rent control and $q_{\sigma}$ with rent control) falls, from 2.00 to 1.54 . Also, at almost all quality levels maintenance (given by $\left.m=a^{2} \phi^{2}\right)$ is lower and depreciation more rapid with rent control. Thus, as intuition suggests, the application of rent control causes housing quality to fall on average. Finally, as already explained, under tenancy rent control, maintenance follows a saw-tooth pattern, rising within each tenancy, and then falling discontinuously between tenancies.

Table 1B: How the opportunistic program changes with a $10 \%$ increase in individual parameters Rent Control 


\begin{tabular}{c|ccccccc} 
& base case & $\alpha=0.55$ & $r=0.04125$ & $\delta=0.033$ & $a=0.23331$ & $e=0.0605$ & $f=0.0055$ \\
\hline \hline$q_{s}^{(1)}$ & 5.4892 & 4.4789 & 4.9126 & 5.1887 & 5.3639 & 7.0485 & 4.9355 \\
$V\left(q_{s}^{(1)}\right)$ & 4.1250 & 3.5945 & 3.5507 & 3.8088 & 4.1394 & 5.5216 & 3.7564 \\
$V\left(q_{s}^{(1)}\right)-\alpha q_{s}^{(1)}$ & 1.3803 & 1.1311 & 1.0944 & 1.2145 & 1.4574 & 1.9974 & 1.2886 \\
$=\widehat{S V}$ & & & & & & & 0.0038 \\
$m\left(q_{s}^{(1)}\right)$ & 0.0036 & 0.0041 & 0.0032 & 0.0034 & 0.0042 & 0.0036 \\
$m\left(q_{L}^{(1)}\right)$ & 0.0138 & 0.0157 & 0.0134 & 0.0138 & 0.0164 & 0.0148 & 0.0137 \\
$m\left(q_{s}^{(2)}\right)$ & 0.0041 & 0.0045 & 0.0036 & 0.0038 & 0.0048 & 0.0046 & 0.0041 \\
$q_{\sigma}$ & 1.5423 & 1.5423 & 1.4529 & 1.3554 & 1.8102 & 1.6966 & 1.5201 \\
$m\left(q_{s}^{(\infty)}\right)$ & 0.0056 & 0.0056 & 0.0048 & 0.0051 & 0.0064 & 0.0068 & 0.0055 \\
$m\left(q_{L}^{(\infty)}\right)$ & 0.0218 & 0.0218 & 0.0199 & 0.0208 & 0.0248 & 0.0263 & 0.0211 \\
$V\left(q_{\sigma}\right)$ & 1.7660 & 1.7660 & 1.5348 & 1.5482 & 2.0522 & 2.1369 & 1.7322 \\
$D W L$ & 0.0361 & 0.0409 & 0.0344 & 0.0386 & 0.0425 & 0.0388 & 0.0356 \\
$D W L / \widehat{S V}$ & 0.0255 & 0.0349 & 0.0305 & 0.0308 & 0.0283 & 0.0191 & 0.0269 \\
PV rent & 4.3599 & 3.8464 & 3.7431 & 4.0344 & 4.4135 & 5.7882 & 3.9872 \\
DWL/PV rent & 0.0083 & 0.0106 & 0.0092 & 0.0096 & 0.0096 & 0.0067 & 0.0089 \\
\hline
\end{tabular}

Note: $q_{s}^{(i)}$ and $q_{L}^{(i)}$ indicate the initial and terminal qualities at the beginning and end of the ith tenancy cycle, respectively.

The absolute deadweight loss due to the application of tenancy rent control is measured as the (pre-construction) value of the program without rent control, which is also the site value at time 0 , $S V$, minus the value of the program with rent control, $S \hat{V}$. Thus, $D W L=S V-S \hat{V}$, which equals 0.0361 , or $\$ 3,610$. What should this be measured relative to? One possibility is the pre-rent-control site value, which is the social value of the land on which the housing unit is built at time $t=0$. We could then say that the application of tenancy rent control dissipates $2.55 \%$ of the social value of land $(D W L / S V \times 100)$. We think it more intuitive to measure deadweight loss relative to the present value of housing rent, or equivalently to measure the average annualized deadweight loss relative to average housing rent. According to this measure, the relative deadweight loss from the application of tenancy rent control is $0.83 \%$. We judge that this degree of relative deadweight loss is "modest but not insignificant", and conjecture that it is substantially smaller than the typical relative deadweight loss due to tenancy lock-in, which we discuss in the next section.

Since there is little empirical work on which to base our calibration, we chose parameter values that give "reasonable" rather than "realistic" results. We should therefore enquire into the sensitivity of our numerical results to parameter values. The other columns of the tables report the results of this sensitivity analysis. Each column records the solution when only one parameter is increased by $10 \%$ relative to its base-case value. Thus, comparing the solution for the base case to the solution for any other column shows the sensitivity of the solution to a change in the corresponding parameter value. All the results can be readily explained in terms of the Figure 3 phase diagram. For example, the $10 \%$ increase in construction cost alters the phase plane in only one respect - the $\phi=\alpha$ line shifts up from 0.5 to 0.55 . The $\dot{q}=0$ line, the $\dot{\phi}=0$ lines with and without rent control, and the trajectories in the phase plane remain unaltered. Since construction becomes more expensive relative to maintenance, profit-maximizing construction quality falls. In the absence of rent control, the optimal trajectory remains the (unchanged) stable arm path, but starts at a lower quality level; with rent control, the first tenancy cycle starts at a lower quality but the steady-state tenancy cycle remains unchanged. Explaining how the absolute and relative deadweight losses are affected by 
the $10 \%$ parameter changes is more involved, but the deadweight loss results are not particularly sensitive to (as measured by the elasticity of the deadweight loss measure to the parameter value) any parameter value ${ }^{20}$. Thus, we assert with fair confidence that the flow deadweight loss due to the commitment-in-maintenance failure deriving from tenancy rent control is of the order of $1 \%$ of rent.

\section{Discussion}

The amount written on rent control has been quite out of proportion to its importance as a housing policy. Economists have devoted so much attention to it because rent control has provided a focal point for studying and debating how regulated - as well as unregulated - housing markets work and how extensive government intervention in the market should be. For example, while this paper has studied how tenancy rent control may generate a commitment-in-maintenance failure, the failure occurs more generally, in all long-term rental contracts for housing and other capital goods for which the owner does all the maintenance, whether or not the contracts are regulated.

The aim of this section is to place the paper in a broader context. The first subsection provides a broader discussion of the effects of tenancy rent control on maintenance. The second provides some general remarks on tenancy rent control.

\subsection{Tenancy rent control and maintenance}

The paper's central model assumed a lot away in order to focus on the commitment failure. This subsection will provide a broader discussion of tenancy rent control and maintenance, by considering how the results of the paper are modified when various assumptions are relaxed.

- The modeling of maintenance

Our model assumed that maintenance is homogeneous but it is not. Some maintenance activities are undertaken daily or weekly, others only every so many years; some are purely cosmetic or counter style obsolescence, while others are invisible but prevent structural deterioration; and so on. Treating maintenance as homogeneous ignores that tenancy rent control may alter not only the level of expenditure on maintenance but also its composition.

While the model assumed that all maintenance is undertaken by the landlord, tenant maintenance is important too. In the absence of rent control, the landlord is typically responsible for maintaining the public areas of a building, but the division of responsibility between landlord and tenant for maintenance within apartments varies considerably. Even when the rent function and tenancy duration are exogenous, which we continue to assume for the moment, there are strategic aspects to this division of responsibility. Both the landlord and the tenant have an incentive to drag their feet hoping that the other will perform the needed maintenance. Also, the landlord but not the tenant is concerned with the quality of the apartment at the end of the tenancy ${ }^{21}$. In this scenario, the application of tenancy rent control has two effects. The commitment-in-maintenance failure

\footnotetext{
${ }^{20}$ Due to the functional form of $\mathrm{P}(\mathrm{q})$, a $10 \%$ rise in e causes more than a $10 \%$ rise in the rent function.

${ }^{21}$ Sweeney (1974b) argues that for this reason maintenance is lower in rental than in owner-occupied housing.
} 
continues to operate, but also the tenant has a stronger incentive to maintain since she realizes that the landlord's incentive is weakened.

- Endogenous tenancy duration

The model assumed that tenancy duration is exogenous and ignored separation costs. Continue to ignore separation costs but make tenancy duration endogenous. In the absence of rent control, the analysis is unaffected since landlord profit is independent of the rate of tenant turnover. Under tenancy rent control, however, since rents are front-end loaded, a tenant has an incentive to stay in her unit longer than she otherwise would ${ }^{22}$. This lock-in effect influences the opportunistic program.

Drawing on the search-and-matching literature, endogenous tenancy duration and this lock-in effect may be modeled as follows. Continue to assume that tenants are (ex ante) identical. Each receives offers to move to a different apartment according to a Poisson process. Each offer indicates the money-equivalent premium the tenant receives from a better match with the corresponding apartment compared to her current apartment, and is drawn from an exogenous distribution. In the absence of rent control, a tenant accepts any offer with a positive value. Define the lock-in value of a tenancy to be the increase in the expected discounted value of quality-adjusted rent a tenant incurs when she vacates her controlled apartment. Under tenancy rent control, a tenant accepts an offer only if its value exceeds the lock-in value of the tenancy. The flow deadweight loss resulting from the tenant's lock-in is the expected value per unit time of the offers she rejects but would have accepted in the absence of rent control. Also, when she vacates her controlled apartment, she essentially transfers the lock-in value to the landlord.

Under tenancy rent control, endogenous tenancy duration further reduces the landlord's incentive to maintain. Recognizing that his profit is decreasing in tenancy duration, a landlord has an incentive to discourage long-term tenancy, and cutting back on maintenance is an effective way to do $\mathrm{so}^{23}$. In the central model, the commitment-in-maintenance failure arose from the application of tenancy rent control and the distortion it created was independent of its severity. With endogenous tenancy duration, however, the more severe is the rent control program, the stronger is the lock-in effect, and the greater the maintenance distortion under tenancy rent control.

- Separation costs

Now extend the model to take into account that the termination of a tenancy entails separation costs, for the tenant the monetary and psychic costs of moving ${ }^{24}$, and for the landlord the cost of finding a new tenant. The combination of endogenous tenancy duration and separation costs alters the landlord-tenant maintenance game. Consider first the situation without rent control, and assume that the market rent function is exogenous so that rent is not a strategy variable. The

\footnotetext{
${ }^{22}$ Recent research on rental housing and job mobility in Denmark (Munch and Svarer, 2002, and Svarer, Rosholm, and Munch, 2005) and the Netherlands (von Ommeren, Rietveld, and Nijkamp, 1999) suggests that the lock-in effect in those countries substantially reduces not only housing mobility but also job mobility.

${ }^{23}$ If he pre-specifies a starting rent, the landlord has an incentive to choose a tenant with a low expected tenancy duration. If he does not pre-specify the starting rent or is willing to offer a discount on the advertised starting rent, he has an incentive to charge a higher starting rent to applicants with a higher expected tenancy duration.

${ }^{24}$ See Raess and von Ungern-Sternberg (2002) for the analysis of a hold-up problem that arises when the tenant's costs of separation are substantial while the landlord's costs of finding a new tenant are negligible.
} 
landlord can threaten to evict the tenant if she undermaintains, while the tenant can threaten to vacate her unit if the landlord undermaintains. The magnitude of their separation costs determines the bargaining power of the two parties. The application of tenancy rent control alters the division of bargaining power in two ways. First, since tenancy rent control is invariably accompanied by eviction and conversion restrictions, its application severely restricts landlords' ability to evict tenants. Second, when a tenant vacates her unit, its lock-in value is transferred to the landlord, which increases her separation costs and decreases his. The former effects weakens the landlord's bargaining power, the latter strengthens it.

- Long-term tenancy, heterogeneous tenants, and tenancy discounts

In rental housing markets without rent control, it is well documented (e.g., Guasch and Marshall, 1987) that longer-term tenants pay less on average in rent. There is no consensus concerning why this occurs, but one explanation is that implicit long-term rental contracts contain a feature analogous to bonus insurance, whereby insurants with good claims records receive premium discounts. This feature not only rewards good tenants but also provides tenants with an incentive to behave well, which includes maintaining well. By undermining this feature, the application of tenancy rent control reduces tenants' incentive to maintain ${ }^{25}$.

- $\quad$ Other noncompetitive features of housing markets

The central model assumed the rental housing market to be perfectly competitive in all respects except for the non-contractibility of landlord maintenance expenditures. Based on there being many buyers and sellers in the housing market, the assumption that the housing market is perfectly competitive was standard twenty years ago. But now there is a substantial literature treating imperfectly competitive aspects of the housing markets. Some of these were treated in the above discussion, either implicitly or explicitly: the non-contractibility of tenant maintenance, separation costs, matching frictions, and asymmetric information regarding tenant type. There is a plethora of other noncompetitive features as well; for example, the heterogeneity of housing units results in the housing market being monopolistically competitive rather than perfectly competitive, so that equilibration occurs via both rent and vacancy adjustment (see, for example, Arnott, 1989, Wheaton, 1990, and Igarashi, 1991). No doubt these other features influence landlord and tenant maintenance decisions, but the effects discussed earlier in this subsection would seem to be the major ones.

- $\quad$ Tenancy rent control is applied to all or part of the market

The model of the paper assumed that tenancy rent control is applied to a single housing unit. Suppose, at the other extreme, that controls are applied to the entire rental housing market. From the perspective of the Muthian model of housing services (Muth, 1969), the production inefficiency generated by the commitment failure raises the marginal cost of rental housing services, causing the equilibrium level of rent per unit of housing service to rise and the equilibrium quantity of housing

\footnotetext{
${ }^{25} \mathrm{~A}$ major cost of being a landlord is dealing with bad tenants, one aspect of which is irresponsibility in maintenance. With the exception of Hubert $(1991,1995)$, the literature has paid little attention to the 'bad tenant problem'. A competitive housing market deals with the bad tenant by not giving her tenancy discounts and by evicting her. Intuitively, evicting a bad tenant "beggars thy neighbor", in this case other landlords. The application of tenancy rent control may therefore counter excessive eviction. But it may also lead to insufficient eviction, and to landlords exercising statistical discrimination against those groups who are disproportionately bad tenants.
} 
services consumed to fall, and induces a substitution towards owner-occupied housing ${ }^{26}$. To extend the model of this paper to the entire rental housing market requires specifying the spatial context of the housing market, treating structural density explicitly, and solving for the equilibrium rent function. Arnott, Davidson, and Pines (1986) presents such a "general equilibrium model" of a quality continuum of housing in a monocentric city in stationary state. In such models, solving for the path of adjustment of the housing market to the application of tenancy rent control would be difficult.

Rent control is often applied to only part of the rental market; for example, in many jurisdictions new construction is exempt (though sometimes later brought under control). If tenancy rent control is applied to only part of the rental market, there are not only the general equilibrium effects ${ }^{27}$ noted above but also complicated sorting effects ${ }^{28}$.

- Details of the rent control ordinance

Olsen (1988) has argued that most analyses of the effect of rent control on maintenance are oversimplified since they fail to take into account the details of the rent control ordinance, as well as complementary policies. Olsen gives the example of a rent control system with rent level decontrol and a cost-pass-through provision. Under this system, the landlord may choose to spend more on maintenance than in the absence of controls since this allows him to raise rents via the cost-passthrough provision, which permits earlier decontrol. Furthermore, if the government is concerned about the adverse effects of rent control on maintenance, it may provide more liberal depreciation under the income tax for capital improvements to rental housing.

Olsen's criticism applies to our model. We assumed that the time path of rent over a tenancy is determined according to a simple formula based on the starting rent. But most actual rent control programs contain other provisions, including cost-pass-through, rate-of-return, and hardship provisions, that alter the landlord's incentives to maintain. Landlord's incentives to maintain are also affected by taxes, which we ignored.

\subsection{Tenancy rent control}

We know of no jurisdiction that has imposed tenancy rent control on a previously uncontrolled rental housing market. Rather, tenancy rent control has been applied as part of a decontrol program from a previously stricter rent control régime. It has therefore been a political compromise between those

\footnotetext{
${ }^{26}$ The application of tenancy rent control would also affect the rental housing market by altering investors' expectations about the future of rent control.

${ }^{27}$ There are several papers in the literature that examine the effects of rent control when it is applied to only a subset of rental housing (e.g., Marks, 1984, and Fallis and Smith, 1984). But all consider first- and second-generation rent control programs, in which the excess demand in the controlled market spills over into the uncontrolled market.

${ }^{28}$ Suppose, for example, that landlords in the controlled sector are unable to condition the starting rent on tenant type but are free to discriminate based on tenant type. Tenants who anticipate long tenancies will prefer to live in controlled housing, but at the same time landlords will want to rent to tenants whom they expect will have short tenancy durations. We conjecture that these conflicting sorting forces lead to a continuum of rational expectations equilibria, in each of which those tenants with the shortest anticipated tenancy durations choose the uncontrolled sector in order to avoid front-end-loaded rents while applications from those tenants whose observable characteristics suggest the longest tenancies are rejected, so that intermediate tenants end up in controlled housing. Other cases, in which landlords can condition the starting rent on tenant type or are not allowed to discriminate among tenant types, yield qualitatively different sorting patterns.
} 
who wish for complete decontrol and those who wish the previously stricter régime to be maintained. This makes it difficult to judge the overall desirability of tenancy rent control. It is unclear not only what to compare tenancy rent control to - the status quo ante, complete decontrol, or other decontrol programs - but also how to treat the political constraints that determine the set of feasible alternative policies.

The evaluation of tenancy rent control is further complicated by disagreement over the appropriate conceptual standard against which to judge it. If a housing market with tenancy rent control is judged against the standard of a perfectly competitive housing market, which entails no transactions costs, symmetric information, and complete insurance markets, among other things, it will be deemed undesirable. But if it is judged against the standard of a real-world unregulated market, with all its imperfections, it may fare considerably better. (This theme is developed in Arnott, 1995.)

If a comparison is made between tenancy rent control and alternative, politically feasible methods of partial decontrol of a previously stricter rent control régime, which would score best most likely depends on empirical magnitudes, as well as program details. But there are no empirical studies comparing tenancy rent control with alternative methods of partial decontrol.

Still, some general statements can be made about the pros and cons of tenancy rent control. Tenancy rent control has the advantage that it eliminates the excess demand phenomena associated with traditional rent control programs. Along with the eviction and conversion restrictions that invariably accompany it, it also provides sitting tenants with implicit insurance against rent increases that improves security of tenure, which tenants value. It gives preferential treatment to sitting tenants, who are disproportionately long-term residents, which is inequitable but at the same time reduces the political opposition to decontrol. Perhaps the most detrimental effect of traditional rent control programs has been their discouragement of rental housing investment. Whether moving from a stricter rent control régime to tenancy rent control provides a substantial stimulus to investment depends on expectations. If landlords are confident that the movement to tenancy rent control will soon be followed by complete decontrol, a boom in rental housing investment can be expected, making up for underinvestment during the years of stricter controls. But landlords may fear that the next surge in rental housing demand will lead to calls for the reapplication of harder controls, as happened in Ontario, and postpone investment until the political climate is more propitious.

\subsection{Concluding comments}

Tenancy rent control regulates rents within a tenancy, based on the starting rent, but allows the starting rent to rise without restriction between tenancies. Many jurisdictions around the world that previously had stricter first- and second-generation rent controls programs have introduced tenancy rent control as a method of partial decontrol.

This paper identified a previously unnoticed inefficiency associated with tenancy rent control, which we termed the commitment-in-maintenance failure. To simplify the argument, we supposed that tenancy durations are fixed. The signing of a unit's lease, which specifies the starting rent, determines the discounted rent over the tenancy. Since the landlord cannot increase the rent he receives over the tenancy by providing better maintenance, the application of tenancy rent control eliminates one of the incentives he has to maintain. The other incentive he has, to increase the quality of the unit at the end of the tenancy, which will increase the rental revenue he receives on 
subsequent tenancies, remains, and encourages maintenance towards the end of the tenancy. According to this line of argument, the application of tenancy rent control leads to the reduction and postponement of maintenance within a tenancy. A counter-argument is that the landlord is free to follow the pre-control maintenance program. If the tenant believes that the landlord will do so, she should be willing to pay the same discounted rent over the tenancy as she would in the absence of controls, and if she does, tenancy rent control has no adverse effects on maintenance. The crux of the difference between the two arguments lies in the ability of a landlord to commit to a maintenance program. We argued that commitment mechanisms in this context are weak, and therefore that the application of tenancy rent control will indeed lead to the reduction and postponement of maintenance within a tenancy. We termed the resulting distortion the commitment-in-maintenance failure of tenancy rent control.

We analyzed the effects of tenancy rent control on the landlord's maintenance program using the Arnott-Davidson-Pines filtering model, which regards the housing market as a continuum of quality submarkets. In order to gauge the magnitude of the distortion due to the commitment-inmaintenance failure, we developed a calibrated example. Since there has been very little empirical work based on this conceptualization of the housing market, we can claim only that the parameter values chosen are reasonable, not realistic. Subject to this caveat, we found the flow deadweight loss due to the distortion to be about one percent of rent.

Our primary intention in writing this paper was to make a positive contribution to the economic theory of rent control and more generally to housing economic theory. However, to put the results in a broader context, at the end of the paper we discussed other channels through which tenancy rent control affects housing maintenance and commented briefly on the strengths and weaknesses of tenancy rent control as a method of partial decontrol.

\section{References}

[1] Arnott, R. 1989. Housing vacancies, thin markets, and idiosyncratic tastes. Journal of Real Estate Finance and Economics 2: 5-30.

[2] Arnott, R. 1995. Time for revisionism on rent control? Journal of Economic Perspectives, 9: 99-120.

[3] Arnott, R. 2003. Tenancy rent control. Swedish Economic Policy Review 10: 80-121.

[4] Arnott, R., R. Davidson, and D. Pines. 1983. Housing quality, maintenance, and rehabilitation. Review of Economic Studies 50: 467-494.

[5] Arnott, R., R. Davidson, and D. Pines. 1986. The spatial aspects of housing quality, density, and maintenance. Journal of Urban Economics 19: 190-217.

[6] Arnott, R. and N. Johnston. 1981. Rent Control and Options for Decontrol in Ontario. Toronto, Canada: Ontario Economic Council, University of Toronto Press.

[7] Arnott, R. and E. Shevyakhova. 2007. Tenancy rent control and credible commitment in maintenance. Boston College WP \#661.

[8] Basu, K. and M. Emerson. 2000. The economics of tenancy rent control. Economic Journal 110: 939-962. 
[9] Basu, K. and M. Emerson. 2003. Efficiency pricing, tenancy rent control, and monopolistic landlords. Economica 70: 223-232.

[10] Borsch-Supan, A. 1996. On the West German tenants' protection legislation. Journal of Theoretical Economics 142: 380-404.

[11] Fallis, G. and L. Smith. 1984. Uncontrolled prices in a controlled market: The case of rent controls. American Economic Review 74: 193-200.

[12] Frankena, M. 1975. Alternative models of rent control. Urban Studies 12: 303-308.

[13] Glaeser, E. and E. Luttmer. 2003. The misallocation of housing under rent control. American Economic Review 93: 1027-1046.

[14] Guasch, J. and R. Marshall. 1987. A theoretical and empirical analysis of the length of residency discount in the rental housing market. Journal of Urban Economics 22: 291-311.

[15] Hubert, F. 1995. Contracting with costly tenants. Regional Science and Urban Economics 25: 631-654.

[16] Igarashi, M. 1991. A Random-Matching and Search Model of a Rental Housing Market. Unpublished Ph.D. thesis. Queen's University.

[17] Iwata, S. 2002. The Japanese tenant protection law and asymmetric information on tenure length. Journal of Housing Economics 11: 125-151.

[18] Kamien, M. and N. Schwartz. 1991. Dynamic Optimization. 2nd ed. Amsterdam: Elsevier.

[19] Marks, D. 1984. The effects of partial-coverage rent control on the price and quantity of rental housing. Journal of Urban Economics 16: 360-369.

[20] Miron, J.R. and J.B. Cullingworth. 1983. Rent control: Impact on income distribution, affordability, and security of tenure. Center for Urban and Community Studies, Toronto.

[21] Munch, J., and M. Svarer. 2002. Rent control and tenancy duration. Journal of Urban Economics 52: 542-560.

[22] Muth, R. 1969. Cities and Housing. Chicago: University of Chicago Press.

[23] Olsen, E. 1988. What do economists know about the effect of rent control on housing maintenance? Journal of Real Estate Finance and Economics 1: 295-307.

[24] Pollakowski, H. 1999. Rent regulation and housing maintenance in New York City. MIT Center for Real Estate Working Paper 79.

[25] Raess, P. and T. von Ungern-Sternberg. 2002. A model of regulation in the rental housing market. Regional Science and Urban Economics 32: 475-500.

[26] Rothenberg, J., G. Galster, R. Butler, and J. Pitkin. 1991. The Maze of Urban Housing Markets. Chicago: Chicago University Press.

[27] Smith, L. 2003. Intertenancy rent control in Ontario. Canadian Public Policy 29: 213-255.

[28] Svarer, M., M. Rosholm, and J. Munch. 2005. Rent control and unemployment duration. Journal of Public Economics 89: 2165-2181. 
[29] Sweeney, J. 1974a. Housing unit maintenance and the mode of tenure. Journal of Economic Theory 8: 111-137.

[30] Sweeney, J. 1974b. Quality, commodity hierarchies, and housing markets. Econometrica 42: 147-167.

[31] Van Ommeren, J., P. Rietveld, and P. Nijkamp. 1999. Job moving, residential moving, and commuting: a search perspective. Journal of Urban Economics 46: 230-253.

[32] Wheaton, W. 1990. Vacancy, search, and prices in a housing market matching model. Journal of Political Economy 98: 1270-1292. 